injuriously affecting casuarina trees in Madras, by Mr. V. S. Iyer, forming Forest Bulletin No. II. The worst offender seems to be the caterpillar of the moth Arbela tetraonis, but the fat grubs of a longicorn beetle are likewise harmful.

No. Io of the serial just quoted is devoted to an account, by Mr. R. S. Hole, of the great outbreak of bark-boring beetle-larvæ in the coniferous forests of the Simla district between I907 and I9II. Five species were involved in this very serious attacls.

From among several articles in vol. vii., part ii., of the Records of the Indian Museum, attention may be concentrated on one by Dr. N. Annandale on the Indian fresh-water soft tortoises, or mud-turtles, of the family Trionychidæ. The author recognises one species and two subspecies which were not included by Mr. Boulenger in the volume on reptiles in the "Fauna of British India," namely, Anderson's Trionyx nigricans, from Chittagong, which has hitherto been insufficiently described, and two local races of the widely spread Emyda granosa. Nor is this all, for Dr. Annandale resuscitates Gray's genus Dogania for Trionyx subplana, on the ground that in the upper shell of this species the entire series of costal plates is separated by mural bones, instead of the last pair meeting in the middle line.

In Records of the Indian Museum, vol. vii., part iii., Mr. J. R. Henderson describes a new tortoise from the Cochin district of southern India, under the name of Geoëmyda sylvatica, Geoëmyda being used as equivalent to Nicoria.

Eri or endi silk, the product of the caterpillar of a large Assamese moth, of which the technical name does not appear to be mentioned, forms the subiect of the first number of vol. iv. of the Entomological Series of the Memoirs of the Department of Agri. culture of India. According to the authors, Messrs. H. Maxwell-Lefroy and C. C. Ghosh, this silk, which from its nature cannot be reeled, is spun and woven in Assam into an exceedingly durable cloth, which readily takes vegetable dyes. Experiments have been undertaken at Pusa with the view of ascertaining whether the cultivation cannot be extended to other parts of India, with results that abpear promising. As the cocoons are not damaged by the moths in making their exit, there is no necessity for killing the latter, which renders the silk acceptable to sects like the Jains, who object to talking life in any circumstances.

R. L.

\section{MAGNETIC PROPERTIES OF ALLOYS.}

VOL. VIII., parts $I$ and 2, of the Transactions of the Faraday Society contain a series of papers which were read at a special meeting of the society held for the general discussion of the magnetic pro perties of alloys. The papers naturally fall into two groups, viz. those dealing with ferrous and with nonferrous alloys respectively.

The iron-carbon and iron-silicon alloys form the subject of an exhaustive paper by Dr. Gumlich, which is of considerable importance in connection with transformer working. He finds that the presence of large amounts of silicon result in the metal, even when quickly cooled, exhibiting a pearlitic structure rather than containing the injurious solid solution of carbon in iron. With prolonged annealing even the pearlite is decomposed into ferrite and temper-carbon. A silicon content of 3 to 4 per cent. is necessary for this effect, so that the good magnetic properties of thin sheet-metal containing less than this amount of silicon must have another origin. Figs. I and 2 show an alloy with $4^{\circ} 5$ per cent. silicon and $0^{\circ} 29$ per cent. carbon. Fig. $I$ is with the metal in the untreated condition, and Fig. 2 after annealing at $975^{\circ} \mathrm{C}$. The annealing has.resulted in the pearlitic structure giving place to enclosures of temper-carbon, and the coercive force has been reduced from $I^{*} 26$ to $0^{*} 6_{5}$ C.G.S. units. A paper by Messrs. Colvert-Glauert and Hilpert, on the magnetic properties of nickel steels, describes a series of tests the results of which are at variance with the view that the peculiar magnetic properties of these alloys are due to the nickel retarding the

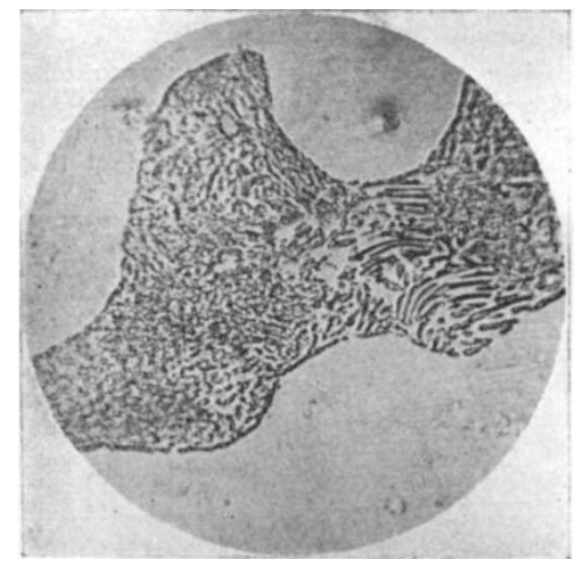

FIG. I. $-4^{*} 5$ per cent. silicon-iron alloy (untreatedi).

change from $\gamma$-iron to $\alpha$-iron. They find all their nickel-iron alloys when quenched at $1200^{\circ} \mathrm{C}$. to be strongly magnetic, and they have come to the conclusion that at that high temperature a strongly mag. netic compound is formed which persists through all subsequent thermal treatments.

Prof. Wedekind's paper on the magnetic properties of compounds in relation to their stoichiometric composition summarises very clearly the present state of

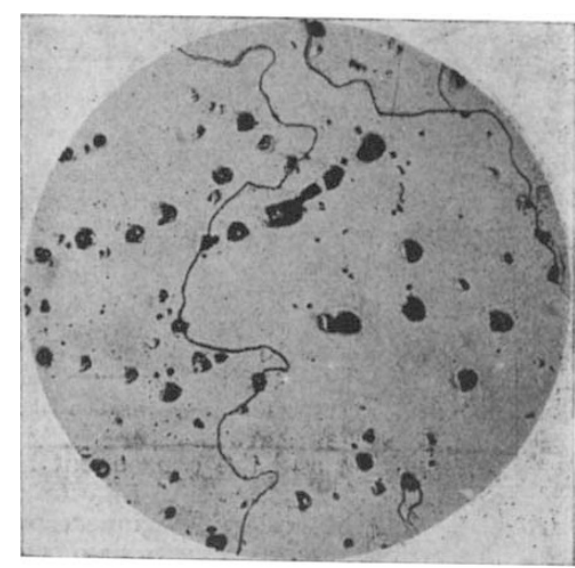

Fig. 2. -4 "5 per cert. silicen-iron alloy (annealed).

knowledge on this important subject. It is found that simple compounds of ferromagnetic metals are throughout essentially more feebly magnetic than are the metals themselves, so far as they represent one particular degree of valency. Simple compounds of the latent-magnetic metals (manganese, chromium, vanadium, and (?) titanium) are generally more strongly magnetic than the metals, and some of the compounds exhibit residual magnetism. The maxiNo. 2260 , VOL. 90] 
mum magnetisation is determined by the stoichiometric composition, especially where several compounds of the same components exist. Manganese, for example, has a maximum in the trivalent condition with such elements as can themselves be trivalent.

Several papers deal with the Heusler alloys. Dr. Ross describes a series of magnetic investigations from which it is concluded that the magnetism of these alloys is associated with the occurrence of solid solutions having the intermetallic compound $\mathrm{Cu}_{3} \mathrm{Al}$ as one constituent, and probably $\mathrm{Mn}_{3} \mathrm{Al}$ as the other. The theory is supported by evidence gathered from examination of the microstructure and from cooling curves. Drs. Knowlton and Clifford, in their paper, also appear to favour the hypothesis of a series of solid solutions as best suiting their magnetic results, but Drs. Heusler and Take still adhere to their belief in a series of ternary magnetic compounds of the general formula $C_{11}$ lin, $A !_{z}$, where $x$ and $y$ can have any of the values $1,2, \ldots$, and $x+y=3 z$. It seems now to be certain that these Heusler alloys-despite their very small hysteresis loss under certain conditions of thermal treatment, \&c.- do not give promise of practical applications in electrical measuring instruments. Their extreme variability, their hardness, and their brittleness are strongly against all commercial applications.

\section{THE ASSOCIATION OF TECHNICAL INSTITUTIONS.}

THE twentieth annual general meeting of the association was held in Birmingham on January $3 \mathrm{I}$, when Mr. J. H. Reynolds, of Manchester, the new president, delivered his presidential address, in the course of which he discussed the progress of elementary education since the Act of 1870 , and contrasted the abundant provision of the present day with the meagreness which prevailed anterior to the Act. He detailed the causes which operated to prevent the realisation of the full fruits of the great Imperial and local expenditure incurred in the establishment and maintenance of elementary education with special reference to the early age of leaving school, and to the absence of proper measures for securing the continued attendance of the children upon suitably designed courses of instruction and training in evening schools during the years of adolescence. He urged the abolition of half-time and the extension of the school age until fourteen, unconditionally throughout the urban and rural areas of the kingdom, and discussed the demand made that the curriculum of the elementary school should be confined to "the three R's," maintaining that there should be made the fullest possible provision for the education and training of the worker's child for his future life as a producer and as a citizen. He further directed attention to the poor physical condition of many thousands of children in the public elementary schools, and appealed for smaller classes and better trained teachers. He dwelt upon the importance of this question of elementary education, since until it is well considered and effectuallv provided, secondary education cannot be adequately established, and any technical education and training of real value directly concerned with a livelihood and based upon scientific principles are impossible.

Education is one, and indivisible, and if there is to be a satisfactory superstructure the foundations must be carefully laid, and the whole scheme made organically complete from the elementary school to the university.

Out of a child population between the ages of thirteen and seventeen amounting to upwards of NO. 2260, vOI. 90]
$1,800,000$, there were only 325,117 enrolled in evening schools. Measures should be enacted requiring all employers to give facilities for the continued education of their employees between the ages of fourteen and seventeen; until that age was reached the child should remain the ward of the schoolmaster.

The Act of 1902 unified under one responsible authority all forms of education, and for the first time in the history of English education gave the means for the provision of a properly organised system of secondary education. The operations of the Technical Instruction Act of 1889 had awakened a new and serious interest in education, derived from the fact that the ill-prepared educational condition of the students made it impossible to impart successfully any satisfactory training in science or technology.

Under the provisions of the Education Act of 1902 numerous old endowed schools all over the country which had become effete for want of effective public control, and of the means to meet the demands of modern requirements, have been revivified, and large numbers of new secondary schools, well staffed and equipped, have been provided. The great drawback to their efficiency is to be found in the short school life, extending to not more than two years and nine months, contrasting unfavourably with the school life of the German gymnasium and the Ober-Real-Schule, extending to nine years, and ending in a leaving examination, admitting without further test to any technical high school or university in Cermany. 11 casures should be taken to ensure a satisfactory length of school life in English secondary schools, concluding with a school-leaving examination giving admission at once to any institution for higher learning.

We have further so to systematise our secondary education that in going from one large urban or other centre to another the scholar will be sure to find a school of similar standing to that he has left. It is to the improvement of the product of the elementary school and in the extension of the school age until fourteen, to a large increase in the number of secondary schools and in the extension of the length of the school life therein, so as to approximate to that of the German and Swiss secondary schools, that we must look for the future growth and efficiency of technical institutions.

Having regard to English conditions these institutions have done an immense service in the past in providing the means of continued education and training for the great mass of the youths engaged in our trades and industries, and English manufacturing industry owes much of its pre-eminence, especially the engineering industries, to the work and influence of these evening schools. In this connection the work of the Department of Science and Art and of the City and Guilds of London Institute has been of high importance and value.

The opportunity of further instruction and training of this character in day classes is much to be desired.

It is satisfactory to note that many of the more important firms, especially in the engineering and chemical industries, are encouraging the admission of a much better type of educated and trained man into their works, and are offering facilitics and inducements based on training age and attainments. As industries grow in respect of the number and varied equipment of the men employed, and in the extent and complexitv of the production, a higher type of man is required, characterised by a better general education, more expert knowledge and practical abilitv. It is realised that "the day of the trained man has come; that of the untrained man is past."

$\Lambda$ new science has come into being, namely "the 